Egyptian

Orthodontic Journal

\title{
ASSESSMENT OF FOUR CEPHALOMETRIC MEASUREMENTS UTILIZED IN EVALUATION OF THE MAXILLARY POSITION IN ANTEROPOSTERIOR DIRECTION
}

\author{
Yasser L Abdelnaby, ${ }^{1}$ Mahasen Taha ${ }^{2}$
}

ABSTRACT:

Aim of the work: The present study was conducted to assess four cephalometric measurements utilized in evaluation of the maxillary position in the anteroposterior direction. The assessment was depending on normality parameters of each measurement and the correlation between them.

Material and Method: Lateral cephalometric radiographs of forty Egyptian adults (20 males and 20 females) with an age range from 19-22 years were selected for this purpose. All had accepted normal occlusions, normal skeletal relationship and balanced profiles. The radiographs were traced and the following measurements were done; SNA angle, $\mathcal{A}$ point to nasion perpendicular distance, condylion to $\mathcal{A}$ point distance, and basion to $\mathcal{A}$ point distance. Statistical analyses were performed to asses these four measurements.

Results: The results revealed that $B a-\mathcal{A}$ was the best measurement satisfied the normal distribution assumption. $B$ a- $\mathcal{A}$ and SNA angle had the highest symmetrical distribution. There were significant correlation between all measurements except between $C o-\mathcal{A}$ and either SNA and $\mathcal{A}-\mathcal{N} p$. In addition, there were significant differences between males and females regarding $C o-\mathcal{A}$ and $B a-A$ measurements.

1- Associate Professor, Orthodontic Department, Faculty of Dentistry, Mansoura University.

2- Lecturer, Orthodontic Department, Faculty of Dentistry, Mansoura University. 
Egyptian

Orthodontic Journal

Conclusion: In assessing the maxillary growth, $B$ a-A measurement satisfied the normal and symmetrical distribution assumption better than the other studied measurements. The males norms of $\mathrm{Co}-\mathcal{A}$ and Ba-A measurements should not be used for females.

\section{INTRODUCTION}

Cephalometric radiography is considered to be one of the most important tools in orthodontic diagnosis and treatment planning. ${ }^{1,2}$ It could be used also for growth prediction and evaluation of treatment outcome. $^{3-5}$ In spite of lateral cephalometric radiography is two dimensional radiography, it has long term utilization, wide-ranging data base and reference values and low cost, make it practical for clinical use. On the other hand, the more recent radiographs such as computed tomography and three dimensional radiography present some disadvantages such as; high cost, high dose of radiation, difficulty associated with the definition of anatomical landmarks and insufficient data base storage. These make it impractical for routine application in actual patients. ${ }^{6}$

Many cephalometric analyses were used to assess the maxillary position related to standardized norms were developed. These norms were derived from an untreated sample of subjects from the same ethnic group, who were selected from a population with so called "ideal" or well balanced faces with normal occlusions. ${ }^{7-23}$ The diagnostic value of cephalometric analysis depends on the accurate and reproducible identification of clearly defined landmarks. Landmark identification is the main source of cephalometric analysis error. ${ }^{24,25}$ Difficulty in identifying cephalometric landmarks are associated with, the images of anatomical structures overlap and that some landmarks are paired with one found on each side of the face consequently, they often appear as double, on coinciding images on lateral radiographs. ${ }^{25,26}$ It is also compounded by the variability of the patient's hard and soft tissues. Another important factor that could affect the validity of different cephalometric analysis is the normality parameters of each measurement. ${ }^{27}$ The data from which the norms were developed have to satisfy the normal distribution assumption. 
Solow $^{28}$ and Järvinen ${ }^{29}$ noted that cephalometric measurements evaluating the maxilla have great variability. Both the types of reference points and their location on the osseous contour caused marked variation of these measurements. In addition, almost all of previous studies evaluated cephalometric measurements either through their reproducibility or the stability of landmarks utilized by each measurement to judge its validity. Therefore, the present study was conducted to assess four cephalometric measurements that evaluate the maxillary position in the anteroposterior direction. Assessment was based on comparing the normality parameters of each measurement and the correlation between them. The studied measurements were; Steiner's SNA angle ${ }^{12}$, Mc Namara's ${ }^{30}$ A point to nasion perpendicular distance and condylion to A point distance, and Clark's ${ }^{31}$ basion to A point distance.

\section{MATERIAL AND METHODS}

The study was based on forty subjects (20males and 20 females). All were Egyptian with accepted normal occlusions, normal skeletal relationship and balanced profiles. The age ranged from 19-22 years. Lateral cephalometric x-ray film was taken for each subject with the teeth in occlusion. Each film was traced on acetate paper. Landmarks and reference points were located. Then the following four measurements for evaluating the anteroposterior position of the maxilla were made (Figure1):

1. SNA angle: the angle between $\mathrm{SN}$ and NA planes. ${ }^{12}$

2. A point to nasion perpendicular distance (A-Np): the horizontal distance between A point and the plane drawn from nasion perpendicular to Frankfort horizontal plane. ${ }^{30}$

3. Condyloin to point A distance (Co-A). ${ }^{30}$

4. Basion to point A distance (Ba-A). ${ }^{31}$

Measurements obtained were corrected for standard magnification. The cephalometric films were retraced and the method error was determined by using Dalhberg's formula which was less than $1 \mathrm{~mm}$ and 1 degree. 


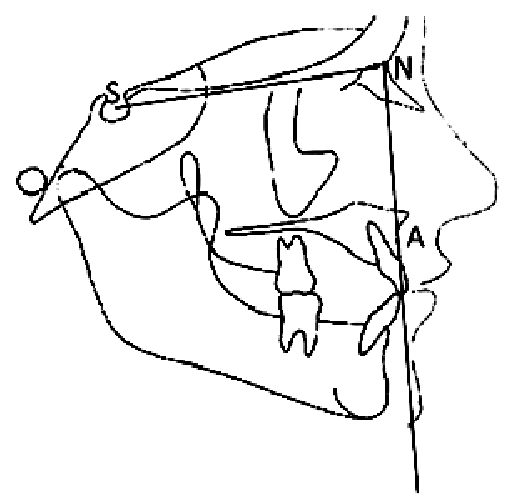

a. SNA angle

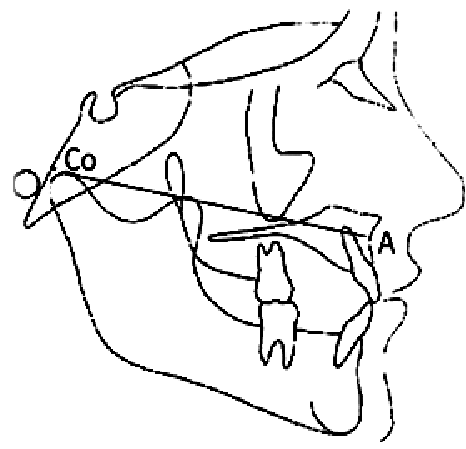

c. Condyloin to A point distance.

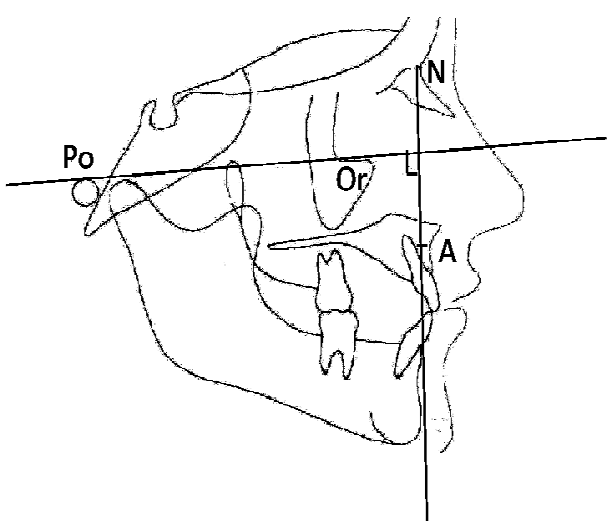

b. Point A to N perpendicular.

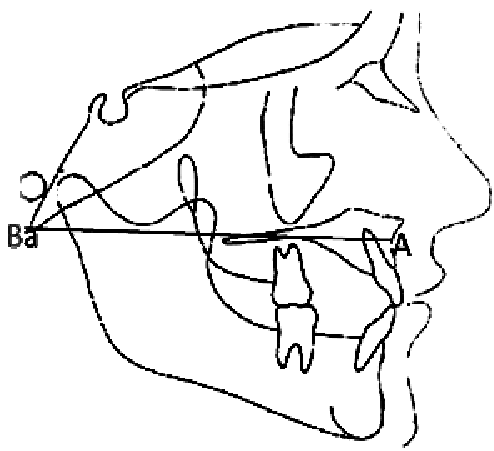

d. Basion to A point distance.

Figure 1: The four cephalometric measurements for evaluating the anteroposterior position of the maxilla.

\section{STATISTICAL ANALYSIS}

The mean and standard deviation were calculated for each group. Normality tests (Kolmogorov-Smirnov and Shapiro-Wilk) and Probability plots (Q-Q plots) were performed to declare if each measurement satisfied the normal distribution assumption. Skewness and Kurtosis tests were also done to evaluate the symmetry of distribution of each measurement. Pearson Correlation Coefficients was utilized to test correlation between the measurements. Student $t$-test was used to detect differences in measurements between males and females. Significance for all statistical tests was predetermined at $\mathrm{P}<0.05$. 


\section{RESULTS}

Descriptive statistics of the four measurements for the whole subjects (males and females) including mean and standard deviations are presented in table 1 . The results of the tests of normality (KolmogorovSmirnov and Shapiro-Wilk) are presented in table 2. Ba-A was the best measurement satisfied the normal distribution assumption. The Q-Q plots and histograms for all measurements were illustrated in figures 2 and 3. The Ba-A was the best measurement matched the normal distribution, where its observations were clustered around the straight line better than the other measurements. In addition, Ba-A observations were distributed in the middle of the histograms better than the other measurements. The results of Skewness and Kurtosis tests revealed that Ba-A and SNA angle had the highest symmetrical distribution (Table 1). The results of correlation coefficient test are illustrated in table 3 . There were significant correlation between all measurements except between Co-A and either SNA and A-Np. The means and standard deviations of males and females and results of $t$ test are presented in table 4. There were significant differences between males and females regarding Co-A and Ba-A measurements.

Table 1: Descriptive statistics of the four measurements of the whole sample (males and females).

\begin{tabular}{|c|c|c|c|c|c|}
\hline \multicolumn{2}{|c|}{ Measurements } & SNA & A-Np & Co-A & Ba-A \\
\hline \multicolumn{2}{|c|}{ Mean } & 81.4000 & 1.2750 & 96.0000 & 98.4750 \\
\hline \multirow{2}{*}{$\begin{array}{l}95 \% \text { Confidence } \\
\text { Interval for Mean }\end{array}$} & Lower Bound & 80.8037 & .8528 & 94.8412 & 97.1896 \\
\hline & Upper Bound & 81.9963 & 1.6972 & 97.1588 & 99.7604 \\
\hline \multicolumn{2}{|l|}{ 5\% Trimmed Mean } & 81.4167 & 1.3056 & 96.0833 & 98.5833 \\
\hline \multicolumn{2}{|l|}{ Median } & 81.0000 & 2.0000 & 96.0000 & 98.0000 \\
\hline \multicolumn{2}{|l|}{ Variance } & 3.477 & 1.743 & 13.128 & 16.153 \\
\hline \multicolumn{2}{|l|}{ Std. Deviation } & 1.86465 & 1.32021 & 3.62329 & 4.01911 \\
\hline \multicolumn{2}{|l|}{ Minimum } & 77.00 & $-1.00-$ & 89.00 & 89.00 \\
\hline \multicolumn{2}{|l|}{ Maximum } & 85.00 & 3.00 & 101.00 & 106.00 \\
\hline \multicolumn{2}{|l|}{ Range } & 8.00 & 4.00 & 12.00 & 17.00 \\
\hline \multicolumn{2}{|l|}{ Interquartile Range } & 3.00 & 2.00 & 6.00 & 5.75 \\
\hline \multicolumn{2}{|l|}{ Skewness } & -.022 & -.187 & -.310 & -.285 \\
\hline \multicolumn{2}{|l|}{ Kurtosis } & -.407 & -1.380 & -1.218 & -.113 \\
\hline
\end{tabular}

Volume 40-December 2011 


\section{Egyptian}

Orthodontic Journal

Table 2: The results of tests of Normality of the whole sample (males and females).

\begin{tabular}{|l|c|c|c|c|c|c|}
\hline \multirow{2}{*}{ Measurements } & \multicolumn{3}{|c|}{ Kolmogorov-Smirnova $^{\mathbf{a}}$} & \multicolumn{3}{c|}{ Shapiro-Wilk } \\
\cline { 2 - 7 } & Statistic & Df & Sig. & Statistic & Df & Sig. \\
\hline SNA & .174 & 40 & .004 & .952 & 40 & .087 \\
\hline A-Np & .259 & 40 & .000 & .855 & 40 & .000 \\
\hline Co-A & .196 & 40 & .000 & .918 & 40 & .007 \\
\hline Ba-A & .110 & 40 & $.200^{*}$ & .975 & 40 & .495 \\
\hline
\end{tabular}

Normal Q-Q Plot of SNA

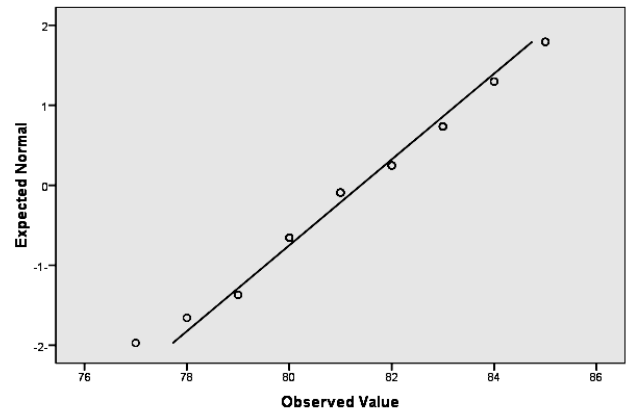

Normal Q-Q Plot of Co-A

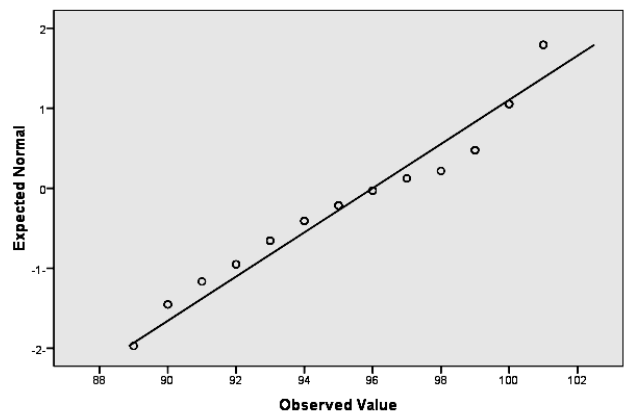

Normal Q-Q Plot of A-NP

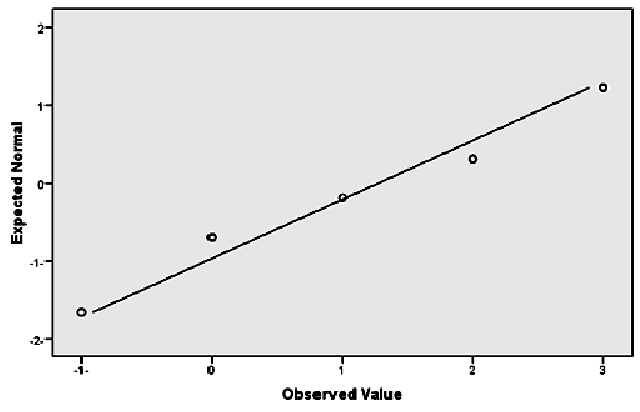

Normal Q-Q Plot of Ba-A

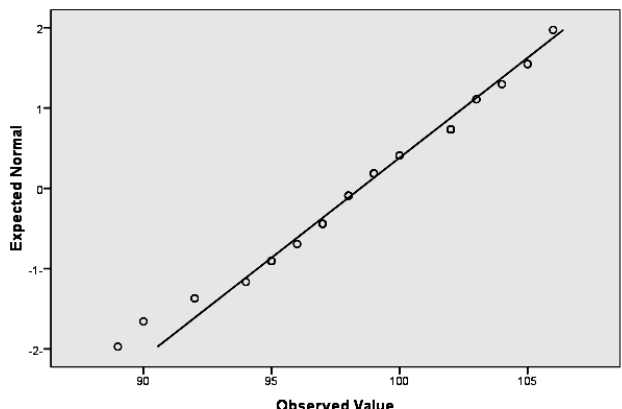

Figure 2: Q-Q probability plots for the four measurements of the whole sample (males and females). 
Histogram

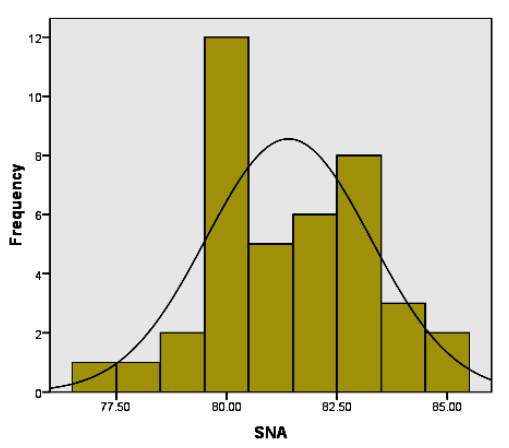

Histogram

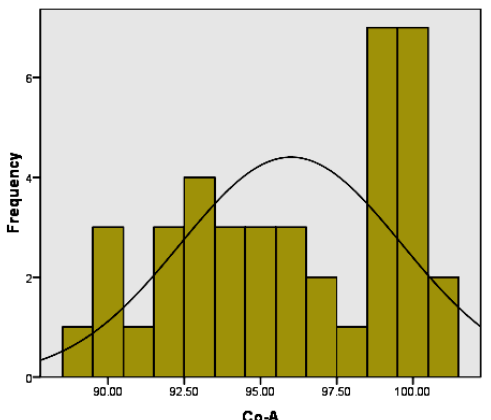

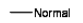

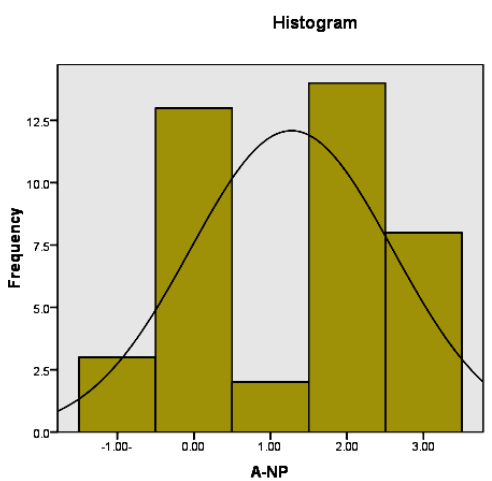

Histogram

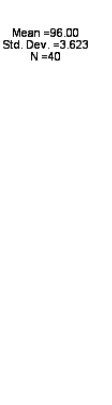

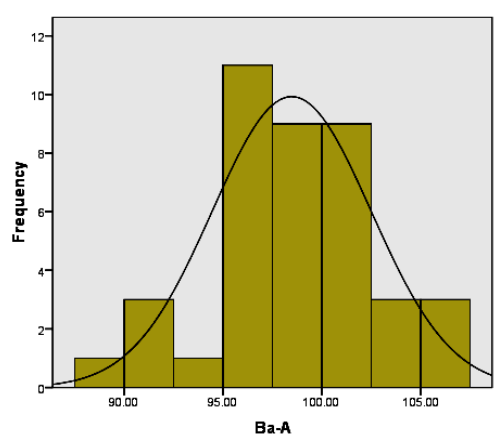

Figure 3: Histograms of the four measurements of the whole sample (males and females).

Table 3: The results of Person Correlation Coefficient test for the four measurements of the whole sample (males and females).

\begin{tabular}{|c|c|c|c|c|c|}
\hline & & SNA & A-Np & Co-A & Ba-A \\
\hline \multirow{3}{*}{ SNA } & Pearson Correlation & 1 & .537 & .243 & $.347^{\prime \prime}$ \\
\hline & Sig. (2-tailed) & & .000 & .131 & .028 \\
\hline & $\mathbf{N}$ & 40 & 40 & 40 & 40 \\
\hline \multirow{3}{*}{ A-Np } & Pearson Correlation & $.537^{\circ}$ & 1 & .300 & $.357^{\circ}$ \\
\hline & Sig. (2-tailed) & .000 & & .060 & .024 \\
\hline & $\mathbf{N}$ & 40 & 40 & 40 & 40 \\
\hline \multirow{3}{*}{ Co-A } & Pearson Correlation & $\overline{243}$ & .300 & 1 & $.769^{\circ}$ \\
\hline & Sig. (2-tailed) & .131 & .060 & & .000 \\
\hline & $\mathbf{N}$ & 40 & 40 & 40 & 40 \\
\hline \multirow{3}{*}{ Ba-A } & \begin{tabular}{|l|} 
Pearson Correlation \\
\end{tabular} & $.347^{\circ}$ & $.357^{\circ}$ & $.769^{\circ}$ & 1 \\
\hline & \begin{tabular}{|l|} 
Sig. (2-tailed) \\
\end{tabular} & .028 & .024 & .000 & \\
\hline & $\mathbf{N}$ & 40 & 40 & 40 & 40 \\
\hline
\end{tabular}

Volume 40 - December 2011 
Table 4: The means and standard deviations of males and females measurements and the results of t-test.

\begin{tabular}{|l|c|c|c|c|}
\hline \multicolumn{1}{|c|}{ Measurements } & Males & Females & T & P \\
\hline SNA & $81.65 \pm 1.75$ & $81.15 \pm 1.98$ & .845 & .403 \\
\hline A-Np & $1.50 \pm 1.23$ & $1.05 \pm 1.39$ & 1.080 & .287 \\
\hline Co-A & $97.90 \pm 2.65$ & $94.10 \pm 3.50$ & 3.864 & .000 \\
\hline Ba-A & $100.55 \pm 3.21$ & $96.40 \pm 3.70$ & 3.781 & .001 \\
\hline
\end{tabular}

\section{DISCUSSION}

Assessment of cephalometric measurements usually made through their reproducibility or the stability of landmarks used by each measurement. The present study was conducted to assess four measurements that evaluated the maxillary position in the anteroposterior direction. However, the criteria of assessment were based on comparing the normality parameters of each measurement and the correlation between them. This statistical approach of assessment is of great importance and has to be considered among other guidelines for choosing cephalometric measurements.

In the present study the cephalometric films were retraced and the method error was determined by using Dalhberg's formula which was less than $1 \mathrm{~mm}$ and 1 degree. This revealed that the measurements had great reproducibility. In addition, they did not largely unaffected by both systematic and random errors. ${ }^{24-26}$ Systematic errors are those related to system as magnification error. On the other hand, random errors are a consequence of uncontrolled variation in the system or technique such as landmark identification error.

The mean values of the present studies (Table $1 \& 4$ ) revealed some variation with those of previous studies. The SNA angle was slightly less than those presented by Steiner ${ }^{12}\left(83^{\circ}\right)$ and McNamara ${ }^{30}\left(83.9^{\circ}\right)$. However, it was closely agreed with those of Downs ${ }^{8}\left(81^{\circ}\right)$, Riede ${ }^{32}\left(82^{\circ}\right)$, Bishara ${ }^{33}$ $\left(81.6^{\circ}\right)$, and east man standards ${ }^{34}\left(81^{\circ}\right)$. The A- Np length was slightly higher than that of McNamara ${ }^{30}(1 \pm 2.7 \mathrm{~mm})$ and much higher than that reported to Chinese population ${ }^{35}(-0.75 \pm 3.6 \mathrm{~mm})$. The Co-A was less than McNamara's ${ }^{30}$ males mean $(100 \pm 6 \mathrm{~mm})$ while close to females 
Egyptian

Orthodontic Journal

mean $(93.81 \pm 2.28 \mathrm{~mm})$. The Ba-A was nearly the same as that of Clark ${ }^{31}$ $(100.75 \pm 4.75 \mathrm{~mm})$. These variations between the results of the present study and the other studies could be attributed to differences in ethnic groups, age range and sample size.

The Histograms and Q-Q probability plots (Figure 2\&3) illustrated that $\mathrm{Ba}-\mathrm{A}$ and SNA angle values clustered around straight line better than the other measurements. Accordingly, they had better normality distribution than both the A-Np and Co-A measurements.

Essential parameters in evaluating the distribution are Skewness and Kurtosis of the measurement values. The former is a measure of symmetry while the latter is a measure of the extent to which observations cluster around a central point. In both tests the closer the value to zero, the more close the distribution to normal. The Ba-A showed the best Skewness and Kurtosis results (-.285, -.113) followed by SNA angle $(-.022,-.407)$. On the other hand, both A-Np and Co-A measurements showed the highest Skewness and Kurtosis values (Table 1). Hence, utilizing these measurements may lead to misjudgment. ${ }^{27}$ This finding was in harmony with those of previous study regarding the departure from normality of certain measurements. ${ }^{28}$

Regarding the correlation between the studied measurements, the results of the present study revealed significant correlation between most of the studied measurements. Hence, they could be interchangeable in the assessment of the anteroposterior maxillary position. However, there was a non significant correlation between Co-A and either SNA and A-Np. Therefore, these measurements were not interchangeable; however their conjunctive use would be advisable for better evaluation of the maxillary position.

The present study also revealed that there were significant differences between males and females regarding Co-A and Ba-A measurements. This finding could be attributed to the differences in facial morphology between the two sexes. The males usually have more pronounced and muscular faces than females. Therefore it is recommended not to use the male norms for female individuals and vise verse during cephalometric analysis for better assessment and accurate diagnosis. 
Egyptian

Orthodontic Journal

\section{CONCLUSION}

- Ba-A and SNA angle presented more normal symmetrical distribution than Co-A and A-Np.

- Significant correlation was found between the studied measurements except between Co-A and either SNA and A-Np.

- Co-A and Ba-A measurements were significantly different in males and females.

\section{REFERENCES}

1. Oliver RS. Cephalometric analysis comparing five different methods. Br J Orthod. 1991;18: 277-283.

2. Fouda M. Sexual dimorphism of cephalometric norms. Al Azher Den J. 1987; 2:563-576.

3. Pae EK, Mc Kenna GA, Sheehan TJ, Garcia R, Kuhlberg A, Nanda R. Role of lateral cephalograms in assessing severity and difficulty of orthodontic cases . Am J Orthod Dentofacial Orthop. 2001;120:254-262.

4. Athanasiou AE. Orthodontic cephalometric. $2^{\text {nd }}$ Ed., 1995; Mosby -Wolfe, Times Mirror International Publishers Limited, England.

5. Kolodziej RP, Southard TE, Southard KA, Casko JS, Jakobsen JR. Evaluation of antegonial notch depth for growth prediction. Am J Orthod Dentofacial Orthop. 2002; 121:357-363.

6. Olmez H, Gorgulu S, Akin E, Bengi AO, Tekdemir I, Ors F. Measurement accuracy of computer -assisted three dimensional analysis and a conventional two dimensional method. Angle Orthod. 2011;81:375-382.

7. Bjork A. The principal of Anderson method of orthodontic treatment, a discussion based on cephalometric X-ray analysis of treated cases. Am J Orthod. 1951;37:437-458.

8. Downs WB. Variation in facial relationships. Their significance in treatment and prognosis. Am J Orthod. 1948; 34:812-840.

9. Downs WB. The role of cephalometric in orthodontic case analysis and diagnosis. Am J Orthod. 1952;38:162-182. 
10. Koski K. Analysis of profile roentgenograms by means of new Circle method. Dent Rec 1953;73:704-713. Quoted from Nanda SK and Sassouni V. Planes of reference in roentgenographic cephalometry. Angle Orthod. 1965;35:311-319.

11. Nanda SK, Sassouni V. Planes of reference in roentgenographic cephalometry. Angle Orthod. 1965;35:311-319.

12. Steiner CC. Cephalometric for you and me. Am J Orthod. 1953; 39: 729-755.

13. Bjork A. Cranial base development: A follow-up x-ray study of the individual variation in growth occurring between the ages of 12 and 20 years and its relation to brain case and face development. Am J Orthod. 1955; 41:198-225.

14. Koski K. The norm concept in dental orthodontics. Angle Orthod. 1955;25:113-117.

15. Krogman WM, Sassouni V. A syllabus in roentogenographic cephalometry. 1957, Philadelphia growth center for research in child growth, Philadelphia, Pennsylvania.

16. Koski K, Virolainen K. The relation between roentgenologic cephalometric lines of reference. Acta Odontologica Scand. 1956; 14: 23-32.

17. Tweed $\mathrm{CH}$. The Frankfort-mandibular incisor angle (FMIA) in orthodontic diagnosis, treatment planning and prognosis. Angle Orthod.1954;24:121-169.

18. Jacobson A. The Wits appraisal of the jaw disharmony. Am J Orthod. 1975;67:125-138.

19. Chang HP. Assessment of anteroposterior jaw relationship. Am J Orthod Dentofacial Orthop. 1987;92:117-122.

20. Sassouni V. A classification of skeletal facial types. Am J Orthod. 1969;55:109-123.

21. Bailey KL, Taylor RW. Mesh diagram cephalometric norms for Americans of African descent. Am J Orthod Dentofacial Orthop. 1998;114:218-223. 
22. Palleck S., Foley TF, Scott JH. The reliability of three sagittal reference planes in the assessment of Class I and Class III treatment. Am J Orthod Dentofacial Orthop. 2001;119:426-435.

23. Rickets RM. The influence of orthodontic treatment on facial growth and development. Angle Orthod 1960; 30:103-133.

24. Broch J, Slagvald O, Rosler M. Error in landmark identification in lateral radiographic headplats. Eur J Orthod 1981;60:111-127.

25. Staburn A, Danielsen K. Precision in cephalometric landmark identification. Eur J Orthod. 1982;4:185-196.

26. Houston WJ. The analysis of errors in orthodontic measurements. Am J Orthod. 1983; 83:382-390.

27. Fouda M, Fawzy K, El-Bialy A, Mahmoud YL. Assessment of four cephalometric measurements utilized in evaluation of the mandibular position. Egyp Dent J. 2006; 52: 849-857.

28. Solow P. The pattern of craniofacial associations. A morphological and methodological correlation and factor analysis study on young male adults. Acta Odontal Scand.1966;24,suppl 46.

29. Jarvinen S. A study of factors causing differences in relative variability of linear radiographic cephalometric measurements. Am J Orthod Dentofacial Orthop. 1987;92:17-23.

30. McNamara JA Jr. A method of cephalometric evaluation. Am J Orthod. 1984;86: 449-469.

31. Clark WK. Twin block functional therapy $1^{\text {st }}$ ed., 1995; Mosby-Wolfe, Times Mirror International Publishers Limited, England.

32. Riedel RA. Esthetics and its relation to orthodontic therapy. Angle Orthod. 1950; 20:168-178.

33. Bishara SE. Longitudinal cephalometric standards from 5 years of age to adulthood. Am J Orthod. 1981;79:35-44.

34. Hamdan AM and Rock WP. Cephalometric norms in an Arabic population. J of Orthodontics. 2000;28:297-300.

35. Wu J, Hagg U, Rabie AB. Chinese Norms of McNamara's cephalometric analysis. Angle Orthod. 2007; 77:12-20. 